\title{
Intervention Strategies of Excessive Masturbation for a 19-Years Youth: Experience of Counseling Intervention
}

\author{
Theresia Shavega \\ Department of Psychology and Special Education, Faculty of Education, The Open University of Tanzania, Dar es Salaam, Tanzania \\ Email: theresia.shavega@out.ac.tz
}

How to cite this paper: Shavega, T. (2020) Intervention Strategies of Excessive Masturbation for a 19-Years Youth: Experience of Counseling Intervention. Open Journal of Therapy and Rehabilitation, 8, 98-109. https://doi.org/10.4236/ojtr.2020.83009

Received: June 9, 2020

Accepted: August 9, 2020

Published: August 12, 2020

Copyright $\odot 2020$ by author(s) and Scientific Research Publishing Inc. This work is licensed under the Creative Commons Attribution International License (CC BY 4.0).

http://creativecommons.org/licenses/by/4.0/

\section{(c) (i) Open Access}

\begin{abstract}
Introduction: Excessive masturbation has for long been reported to affect youths with intervention strategies to intervene with this problem remaining unclear. This study aimed at determining the underlying factors for excessive masturbation, its effects and intervention strategies used. Methods: This was a case study design for a youth aged 19 years; affected by excessive masturbation. Data were collected through individual counseling and intervention. It involved 15 counseling sessions which were run in nine months in a three weeks interval. The sessions involved narration and exploration of the causes and effects of masturbation. Counseling intervention was built in a vicious circle. Results: Several factors, effects and intervention strategies were identified, reported and discussed in this study. Main causes were such as stories from friends and pornographic videos. Effects were multiple risk behaviors and health problems. Counseling model for individual was developed. Conclusion: The study indicates that there are multiple causes and effects of excessive masturbation. Since masturbation is secretly done, the effects are not widely known to many people. Most of these effects are long-term which affects a person psychologically, physically, socially and morally.
\end{abstract}

\section{Keywords}

Masturbation, Excessive Masturbation, Intervention Strategies, Counseling

\section{Introduction}

Masturbation is part of sexual behavior practices which is considered normal or developmentally appropriate from early childhood. Masturbation is viewed as a normal part of sexual development in children and youths [1] [2] [3]. Examples 
of common sexual behavior in children are such as viewing another person's genital and touching their genitals [4]. Masturbation has been reported as healthy and used as a way of expressing human sexuality especially for youth [2] [5]. Studies report that youths comment masturbation as being safer compared to other sexual practices: explaining that it carries no risks of pregnancy and sexually transmitted infections and its benefits on sexual and emotional health. [6] [7] reports masturbation as the most common sexual practice among the Iranian teenagers. The scenario indicates that masturbation is part of sexual experimentation in youths and it becomes a risk when it is done frequently. Masturbation becomes a problem especially when it is overdone which may lead to hypersexuality or sexual addiction; which may cause behavioral disorder such as interfering social interaction [4] [5]. Masturbation leads into Sex addiction which is associated with maladaptive behavioral response [8] [5] that can have serious adverse functional consequences later in life [8] [9].

Excessive masturbation is linked to psychological factors such as depressive symptoms, anxiety, loneliness, low self esteem and insecure attachment life styles and experiential avoidance [10] [11] [12] [6]. [13] noted that many teenagers who practice excessive masturbation are at higher risk of suffering from mental disorders.

Excessive masturbation has also been reported to damage the sexual organ due to frequent scratching, premature ejaculation, infertility, forgetfulness, aggression, anger and loneliness [11] [14]. Research further report that when an adolescent reaches a stage of compulsive masturbation, $s($ he) is at risk of feeling guilty, shame and angry, self isolation, which may subsequently lead into lack of self-confidence as $s($ he) grows [9]. Furthermore, people who practice masturbation are reported to experience stigma due to community negative perception of masturbation [6]. [15] says that according to the Bible, sex meant to be pleasurable in marriage between a man and a woman; thus, out of this, it is not acceptable. Devendra (2017) points out several effects of masturbation such as effects on body health because it wastes a lot of semen. Furthermore, extreme masturbation may weaken bones; this happens when a person ejaculates white part of phosphorus, carbon and other minerals which are extracted from bones.

Research indicates that prevalence on masturbation is high among males than in females. For example, [14] found out that males have been perceived to masturbate more often than females. [6] did a study in USA and reported that across age groups, males $(73.86 \%)$ reported to practice masturbation more frequently than females (26.14\%). According to [16] in Australian study, 58\% males and $48 \%$ females aged 15 - 18 years were reported to practice masturbation. Studies indicate that people don't discuss about masturbation because is perceived as unfavorable. For example, it has been reported that parents face difficulty discussing masturbation with their adolescent's because this is an unfavorable topic for discussion [17] [18]. [18] further argues that although several teens would like to stop from masturbation, they find it difficult since no one would like to 
talk and discuss about it, including parents who tend to ignore it. For example, a quotation from [18]) confirms this argument.

"I am 15 years old. I am suffering from a porn and masturbation problem and I have no one whom I trust to share this problem with. I am an Atheist and I would really appreciate if someone would like to help me. Please I request your help."

Masturbation is practiced at an early age and with time they become addicted from which majority are suffering from it. Studies reveal that masturbation, especially excessive masturbation is becoming so serious since teenagers have access to the internet as well as pornographic videos via tube sites which become part of their stories [19] [20]. [19] argues that in normal way teens who watch pornography are susceptible to sexual response which may require them to masturbate regularly which leads to compulsive masturbation disorder. Furthermore, research reports suggest that internet pornographic constitutes a supernormal stimulus in youth [20] [21]. With time, a person identifies him/herself as being addicted to porn because $s /$ he is unable to regulate his/her behavior towards porn, which may interfere with everyday life [22].

In African countries, masturbation is regarded as a taboo but is practiced by both, youths as well as adults. [23] found that in Tanzania adolescents practice masturbation as part of their sexual practices. However, in Tanzania there are few studies about masturbation and no known studies about intervention on excessive masturbation especially among the youth who are affected by pornographic video.

\section{Counseling interventions for the person affected by masturbation}

Counseling intervention is a unique interrelationship between a client and a counselor that aims to create change of personal development, professional development, social adjustment and behavior change. Both, a counselor and a client contribute actively to the process of change. A counselor has a role of helping a client to explore his/her inner world of the self. This approach is guided by Rogers' theory of behaviorism which was developed to help a client to develop ability to explore his or her inner world of the hidden world and new aspects in his/her behavior [24] [25]. The theory acts as a guideline during establishing a relationship between a counselor and client. The theory puts a client at a focal point hence regarded as a client-centered approach. According to the theory the role of the client is to explore which is necessary for changing feelings, thoughts and behavior during counseling intervention. A client follows a journey of treatment and the treatment plan is built around the problem. During intervention, new problems may arise and thereafter modified.

\section{Masturbation and treatment}

Masturbation is viewed as a developmentally normal behavior in children. When masturbation is practiced beyond normal sexual behavior and causes injuries or pains, treatment becomes necessary [26] [27]. This is to say when a child or an adolescent reaches a stage of excessive masturbation, treatment or 
intervention becomes necessary. Different treatment techniques have been suggested to solve a problem of excessive masturbation. For example, electrical shock was used to punish a child who practiced masturbation [28] Negative punishment such as taking away of items from the child was also applied to stop masturbation in children [29] Furthermore, a hormonal drug therapy was also reported to be used to reduce sexual drive in children [30]. However, these techniques might not be helpful to reduce excessive masturbation because they inflict harm in the child.

Clinical psychologists used positive intervention to manage masturbation of the child. For example, [28] reported to apply positive treatment by involving parents in managing masturbation of a 9-year-old child. The treatment involved age appropriate education, reinforcement, distraction, redirection and sometimes negative punishment. These treatments were used to help children who practiced masturbation in public. However, these treatment techniques are not helpful for adolescents since it is not common for a youth to practice masturbation in public.

\section{Case illustration about masturbation by the client}

The client is aged nineteen (19) years old, an adolescent male who was affected by excessive masturbatory behavior since he entered into puberty. He started masturbation at the age of fourteen (14) years when he was in form two in secondary school. He got knowledge of masturbation and its advantages from his friends. Among the perceived advantages of masturbation were such as it being safe from HIV/AIDs, cheap, convenient and no negotiation about it, to mention a few. He explained that in the first three months he used to practice masturbation once a day and with a maximum enjoyment. Later on he became used to masturbation and the frequencies increased up to seven times per day. No single night was skipped without masturbating. During day hours, masturbation was done in the toilets.

In a Tanzanian context, parents don't guide their male adolescents on how to cope with adolescence and risks associated with sexuality including masturbation. This was a story from a client, which was a source of counseling intervention.

Masturbation and intervention measures have been widely discussed in developed countries; however, evidence of masturbation intervention from developing countries like Tanzania is not clear. Furthermore, no study addressed intervention strategies taken to help youths who have been affected by excessive masturbation especially in a Tanzanian context. This study therefore aims to address effects of masturbation and intervention measures for youths who are affected by masturbation through counseling. Specific objectives of this study are:

1) Developing counseling model for individual counseling;

2) To explore the causes and effects of excessive masturbation in youths through counseling services;

3) To determine intervention measures used to manage excessive masturbation through counseling intervention. 


\section{Method}

\subsection{Participants, Design and Process of Counseling Intervention}

This was an intervention case study design study aimed at helping a youth, aged 19 -years-old who was affected by excessive masturbation. Only one youth participated in the intervention through different counseling sessions. This is also known as a single subject research, which is very common in the field of counseling [31]. Single subject research was opted because masturbation practice is sensitive to an individual. The design allowed a counselor and client to determine the changes of behavior over time.

The behavior of an individual was observed repeatedly over the course of intervention.

Intervention counseling sessions started in March 2018 to October 2018. There were 15 counseling sessions, which were run in nine (9) months of three (3) to four (4) weeks interval. Counseling sessions involved narration and exploration of the causes and effects of masturbation. Narration was followed by exploration of the problem through unstructured interview. Every counseling session was followed by an intervention of not less than three weeks, which was also followed by counseling session. Counseling intervention was built on a vicious circle.

\subsection{Data Collection Methods}

This was a self-report throughout the counseling and intervention period. A client kept a daily diary, which he put information by noting frequencies of masturbations per day. He also kept records of the causes of masturbation for each day. In case of behavior improvements, the client kept records on issues, which contributed in reducing frequencies of masturbation. On the other hand, a counselor kept records on the progress made and problems faced by the client as reported in each counseling session.

\subsection{Ethical Issues}

Since counseling session was personal the information obtained from the counseling session was treated as confidential. Nobody was and will be informed about the name of the client including his parents and brother. The session was conducted in a special room used for counseling. The counselor was taking notes during the counseling session under the consent of the client. The counselor sought consent from the client to publish the information obtained from the counseling sessions and intervention. Publication agreement was made under the condition that his name should not appear anywhere in this paper.

\section{Findings}

The study aimed at exploring causes and effects of excessive masturbation. Through counseling it was revealed that the main causes of masturbation were stories of masturbation from friends. The source of the problem was put very clear by the client; see the quotation below: 
"I heard about masturbation when I was in standard seven but got more familiar to masturbation when I was in form two. Young boys approve masturbation because it is safe from HIV/AIDS and STDs, not expensive, you can do at your convenience. If you can masturbate you are considered a real man." (client)

Another cause of masturbation as reported by the client was pornographic videos. The client reported that most of the time he watched the videos especially when he was idle; which increased frequencies of masturbation from once to seventh times per day; see the quotation below:

"I frequently watch pornographic videos in the YouTube using my mobile when I'm alone and idle; this increases frequency of masturbation. Frequencies increased from once to seventh times per day." (client).

We explored whether masturbation has effects. According to the client, masturbation has short-term gratification which is regarded as positive effect but when it becomes excessive it is unhealthy. He explained that excessive masturbation affects academic performance; once you involve in masturbation it is very difficult to concentrate on studies. Since masturbation including watching pornographic videos are done in a secret setting they lead into loneliness. It was further revealed that a youth who concentrate on an excessive masturbation is more likely to fall behind of many things and it is difficult for her/him to cope with his peers in academic and social issues; quotation below support this argument:

"After masturbating I always feel so tired in such a way that I cannot do anything including studies; a situation, which made me angry, lonely and anxious. It is difficult to establish relationship with my peers. Since masturbation is done in private, most of the time I prefer to be alone, a situation which puts more into more risks." (client)

It was revealed that excessive masturbation was associated with risk behaviors. Since masturbation was practiced in a private setting and sometimes practiced while watching pornographic video displaying masturbation; the practice therefore was associated with idleness, loneliness, anger, reticent and anxiety as revealed in the quotation below:

"Most of the time I preferred being alone because pornographic videos are watched in private situations so I felt lonely, anxious and sometimes angry because I didn't like the situation I go through." (client)

Furthermore, a client reported that after ejaculation he experienced pains in the spinal cord and the reproductive part, which made him uncomfortable most of the time. The quotation below supports this statement:

"Masturbation is associated with long-term effects of the health and behavior especially among the youth. For example, as I scratched my reproduc- 
tive organ I felt severely pains in the spinal cord after ejaculation, after getting used to I preferred privacy all the time, as a result I felt lonely, angry, situations which makes me fall behind of everything in terms of behavior and academically." (client)

We explored about the intervention strategies used to intervene excessive masturbation. This was a result of counseling interventions as it was revealed from discussion from different counseling sessions. The client reported intervention strategies which helped him to reduce frequencies of masturbation; see the quotations below.

I joined a group of choir in our church, and I established a group of writing articles for youths which can be published in a daily news magazine. These activities are making me busy and I forget even watching pornography videos as a result masturbation frequency have reduced from 7 times to $1 / 0$ per day. (client)

I schedule my time also for cleaning our compound at an activity which solved the issue of idleness and partly reduced frequency of watching pornographic video and frequencies of masturbation was reduced to nill. (client)

From the quotations above we can say that his involvement in writing activities enabled him to solve the problem of idleness and loneliness to a greater extent. Through these activities, the client partly controlled watching pornography video as well.

\section{Discussion}

\subsection{Counseling and Intervention Model}

During the counseling, we developed a model, which guided us during the counseling sessions and intervention sessions. Since there are few studies on masturbation and related intervention services, it was difficult to find a model to guide us during the counseling sessions. The following model in Figure 1 was developed and guided the counseling session and intervention.

The model below indicates that counseling intervention occurred in a vicious circle. The first session started with exploration of the problem. This is a stage where a client narrated a story about masturbation and disclosed advantages and risk behaviors associated with excessive masturbation. The client explained the problems of excessive masturbation and the severity as well as the way it affected him. The counselor noted the situation and the severity of the problem. The counselor explored more about the problem through explorative question; which helped a counselor to identify more about events leading to masturbation and excessive masturbation. Explorative interview helps a client to think about intervention measures as supported by [32] that questions will help a client to think through what he can do to protect himself from excessive masturbation in future. 


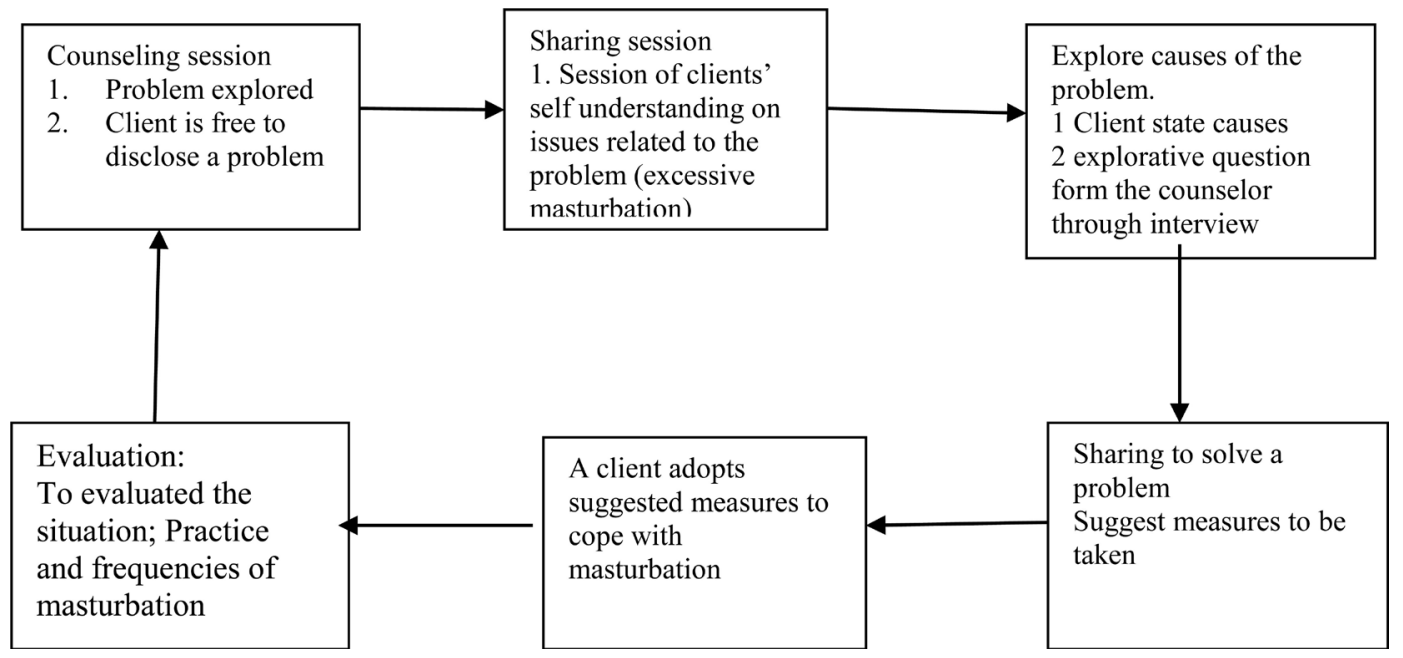

Figure 1. Model prepared by a counselor during intervention.

This session was followed by a sharing session about strategies that can be used to control excessive masturbation. Both, counselor and client suggested measures that could be used to control masturbation. The client adopted the proposed strategies. This session was followed by an evaluation of the strategies/measures taken to solve the problem of excessive masturbation. In this session, a client disclosed measures, which helped him to reduce the problem.

In case of an improvement observed the client put clear measures or strategies used to reduce the problem. At this stage, the session started again in stage one to explain the problem; so, the model of counseling session as developed and proposed in this study was in a vicious circle; which involved disclosing a problem, understanding the problem; exploring of the problem, stating causes, effect and strategies, all these used to solve the problem and finally evaluation. In every stage, the focus was to solve the problem through intervention.

\subsection{Causes and Effects of Excessive Masturbation}

This study aimed to explore the underlying causes and effects of masturbation. The causes were explored in every counseling session under the assumption that causes may differ according to the context and time. The common mentioned causes were stories of masturbation from friends and peers in school. It was found that stories of masturbation are common in primary and secondary schools especially for male's students. In normal way, friends, especially peer groups are significant sources of information and behavior among youths. These findings are in line with that of [33] who point out friends in school to be the main sources of information about sexual practice, including masturbation. Youths prefer to experiment what their peers approve regardless of their negative effect.

Pornographic video has been pointed out as another source of masturbation, which contributed to excessive practice of masturbation. These videos can be found in CD's, you tube and other internet sites. When youth spend long time watching visual sexual stimuli displaying masturbation, they're at risk of devel- 
oping a habitual behavior to masturbation. The videos have instant stimulation to masturbation since as one watches them, the more likely s/he may learn different styles of masturbation thus, practice it excessively. Other Researchers also report pornography to be among the sources of sexual practices including masturbation [34] [12] [33]. In addition, mobiles are commonly used among youths to search pornographic materials as supported by the following quotation:

"I usually watch masturbation practice using my mobile phone because it is easy to use and helps to keep secret as masturbation should be a secret." (client)

Findings revealed that excessive masturbation has a number of effects. Firstly, masturbation affects studies and social life skills. When a person engages in excessive masturbation, it becomes difficult for him/her to concentrate on studies or any other social activities. The findings are in line with that of [35] who report that people who engage in masturbation cannot be able to focus on their work and their social life.

Secondly, it is unhealthy because once one engages in masturbation; he is more likely to practice masturbation several times per day. This may affect the person such that he may feel extremely tired and weak. In some cases, the practice may bring about pains in the reproductive organ due to frequent scratching. In addition, frequency ejaculation may result into pain on the spinal cord as well as joints' weakness. [13] reported the same effects of masturbation. In addition, excessive masturbation may lead into maladaptive behavioral response and finally behavioral disorder [8] [4] [5].

Thirdly, this study reveals that a person who is affected by excessive masturbation may feel shameful and thus isolate himself from other people; this leads to loneliness. In addition to this, the person becomes uninterested to the opposite sex, i.e. females. Furthermore, psychological factors such as depressive symptoms, anxiety, loneliness, low self esteem and insecure attachment life styles and experiential avoidance were reported to be associated with excessive masturbation. The findings are in line findings of [10] [11] and [12]. [13] noted that many teenagers who practice excessive masturbation are at higher risk of suffering from mental disorders, the findings concur with findings in this study. Furthermore, findings in this study revealed that the client has poor social skills which interfere with socialization processes hence loneliness; the findings are in line with that of [22].

\subsection{Intervention Strategies Used to Manage Excessive Masturbation}

The study aimed at exploring interventions strategies used to solve a problem of excessive masturbation. This was an intervention study which involved several counseling sessions and interventions. The client gained self-skills which helped him to manage excessive masturbation. The management of excessive masturbation was indicated by the decrease in frequencies of masturbation from seven times per day to once per month and finally no masturbation at all. The study 
revealed several strategies which helped a client to manage excessive masturbation, which was through various activities among them being regular exercise. For example, he became an active choir member at the church and also spent his extra time doing cleanliness at home. These findings are in line with that of [36] who report that preference on healthy activities such as regular exercises help to control excessive masturbation. Furthermore, findings in this study revealed that the client established a writing page in the magazine for the purpose of fighting excessive masturbation which is active to date. In this page, he reported to prepared stories which were published in the magazine whereas, most of these activities were voluntary and became essential in solving a problem of loneliness. Activities therefore may replace watching pornographic video, which is healthy.

\section{Conclusion}

We were able to develop a model which worked successfully in the context of this study, which was suitable for individual counseling. The study indicates that there are multiple causes and effects of excessive masturbation. Since masturbation is secretly done, the effects are not widely known to many people. Factors such as stories about masturbation, pornography video and idleness were pointed out as the sources of excessive masturbation. Anger, anxiety, poor social skills depression and pains on the spinal cord and reproductive organ were among the health and behavior risks associated with excessive masturbation. Most of these effects are long-term which affects a person psychologically, physically, socially and morally. According to the findings, healthy practices such as joining groups, avoid watching pornography and counseling are suitable intervention strategies towards excessive masturbation. Furthermore, the integration of the client into meaningful social contacts might have been the causal agent that has reduced frequencies of masturbation. However, the results of this study may not be generalized among the youths due to its nature, that is, case study design. A study of this nature in future should involve large group of youths to explore their perceptions on causes, effects and intervention strategies towards excessive masturbation. The study recommends that youths should be educated on the effects of excessive masturbation and sexual addiction as well as intervention strategies available for those who are already affected.

\section{Conflicts of Interest}

The author declares no conflicts of interest regarding the publication of this paper.

\section{References}

[1] Kaestle, C.E. and Allen, K.R. (2011) The Role of Masturbation in Healthy Sexual Development: Perception s of Young Adults. Archives of Sexual Behavior, 40, 983-994. https://doi.org/10.1007/s10508-010-9722-0

[2] Ray, J. and Afflerbach, S. (2014) Sexual Education and Attitudes towards Masturbation. Journal of Undergraduate Research at Minnesota State University, 14, Article 8. 
[3] Shapiro, T. (2008) Masturbation, Sexuality and Adaptation: Normalization in Adolescent. Journal of the American Psychoanalytic Association, 56, 123-143. https://doi.org/10.1177/0003065108315687

[4] Kellogg, N.D. (2010) Sexual Behavior in Children's and Management. American Family Physician, 82, 1233-1238.

[5] Walsh, A.L. (2000) Improve and Care; Responding to Inappropriate Masturbation in People with Severe Intellectual Disabilities. Sexuality Disability, 18, 27-39. https://doi.org/10.1023/A:1005473611224

[6] Robbins, C.L., Shick, V. and Reece, M. (2011) Prevalence, Frequency, and Associations of Masturbation with Partnered Sexual Behaviors among US Adolescents. Archive of Pediatric and Adolescent Medicine, 165, 1087-1093. https://doi.org/10.1001/archpediatrics.2011.142

[7] Sharafi, M.R. (2000) World of the Teenagers. Culture Institution of Education, Tehran.

[8] Kafka, M.P. (2010) Hypersexual Disorder: A Proposal Diagnosis for DSM-V. Archive of Sexual Behavior, 39, 377-400. https://doi.org/10.1007/s10508-009-9574-7

[9] Van Gordon, W., Shonin, E. and Griffiths, M.D. (2016) Meditation Awareness Training for the Treatment of Sex Addiction. Journal of Behavioral Addictions, 5, 363-372. https://doi.org/10.1556/2006.5.2016.034

[10] Dhufaar, M.K. and Griffiths, M.D. (2014) Understanding the Role of Shame and It's Consequences in Female Hypersexual Behavior, a Pilot Study. Journal of Behavior Addiction, 3, 251-237. https://doi.org/10.1556/JBA.3.2014.4.4

[11] Dwulit, A.D. and Rzymski, P. (2019) The Potential Association of Pornography Use with Sexual Dysfunctions: An Integrative Literature Review of Observation Studies. Journal of Clinical Medicine, 8, 1-15. https://doi.org/10.3390/jcm8070914

[12] Levin, M.E., Lillis, J. and Hayes, S.C. (2012) When Is Online Pornography Viewing Problematic among College Males? Examining the Moderating Role of Experiential Avoidance. Sexual Addictive and Compulsivity, 19, 168-180.

[13] Kamkar, M. and Jabarian, S. (2007) Happiness, Masturbation and Teenagers: Approaches and Religious Beliefs, Sexual Health Symposium, Tehran.

[14] Shekarey, A., Sedaghat, R.M., Mazdai, Kh. and Mohammadi (2011) Masturbation, Prevention and Treatment. Procedia Social and Behavioral Sciences, 30, 1641-1646. https://doi.org/10.1016/j.sbspro.2011.10.318

[15] Mahoney, K. (2019) What Does the Bible Say about Masturbation? https://www.learnreligions.com/the-bible-says-about-masturbation-712791

[16] Smith, A.M., Rosenthal, D.A. and Rechler, H. (1996) High Schoolers' Masturbatory Practices: Their Relationship to Sexual Intercourse and Personal Characters. Psychology Report, 79, 499-509. https://doi.org/10.2466/pr0.1996.79.2.499

[17] Fine, M. and McClelland, S.I. (2006) Sexuality, Education and Desire. Still Missing after All These Years. Harvard Educational Review, 76, 297-338. https://doi.org/10.17763/haer.76.3.w5042g23122n6703

[18] McKenna, C. (2016) Masturbation: 3 Tips of Talking to Teens. https://protectyoungeyes.com/masturbation-3-tips-for-talking-to-teens/

[19] Griffths, M.D. (2016) Compulsive Sexual Behavior as Behavioral Addiction: The Impact of Internet and Other Issues. Addiction, 111, 2107-2108.

https://doi.org/10.1111/add.13314

[20] Hilton, D.L. (2013) Pornography Addiction: A Supernormal Stimulus Considered in the Context of Neuroplasticity. Socioaffective Neuroscience \& Psychology, 3, 2076. https://doi.org/10.3402/snp.v3i0.20767 
[21] Negash, S., Sheppard, N.V.N., Lambart, N.M. and Fincham, F.D. (2015) Trading Later Reward for Current Pleasure: Pornography Consumption and Delay Discounting. Journal of Sex Research, 53, 689-700. https://doi.org/10.1080/00224499.2015.1025123

[22] Sniewski, L., Farvid, P. and Carter, P. (2018) The Assessment and Treatment of Adult Heterosexual Men with Self-Perceived Problematic Pornography Use; a Review. Addictive Behaviors, 77, 217-224. https://doi.org/10.1016/j.addbeh.2017.10.010

[23] Kazaura, M.R. and Masatu, M.C. (2009) Sexual Practice among Unmarried Adolescents in Tanzania. BMC Public Health, 9, Article No. 373. https://doi.org/10.1186/1471-2458-9-373

[24] Rogers, C.R. (1959) A Theory of Therapy, Personality and Interpersonal Relationships, as Developed in the Client-Centered Framework. In: Koch, S., Ed., A Study of Science, McGraw Hill, New York, 184-256.

[25] Rogers, C.R. (1977) Carl Rogers on Personal Power. Delacorte Press, New York. https://doi.org/10.1177/0003065108315687

[26] Hornor, G. (2004) Sexual Behavior in Children: Normal or Not Normal? Journal of Pediatric Health Care, 18, 57-64. https://doi.org/10.1016/S0891-5245(03)00154-8

[27] Mallants, J. and Casteels, K. (2008) Practical Approach to Childhood Masturbation: A Review. European Journal of Pediatric, 167, 1111-1117. https://doi.org/10.1007/s00431-008-0766-2

[28] Patterson, T. and Scott, C. (2013) Behavioral Management of Inappropriate Masturbation in an 8-Year-Old Girl. Child and Family Behavioral Therapy, 35, 256-263. https://doi.org/10.1080/07317107.2013.818907

[29] Armstrong, K.J. and Drabman, R.S. (1998) Treatment of a Nine-Year-Old Girls' Public Masturbation Behavior. Child and Family Behavior Therapy, 20, 55-62. https://doi.org/10.1300/J019v20n01 04

[30] Carlson, G., Taylor, M. and Wilson, J. (2000) Sterilization, Drugs Which Suppress Sexual Drive and Young Men Who Have Intellectual Disability. Journal of Intellectual and Development Disability, 25, 91-104. https://doi.org/10.1080/13269780050033517

[31] Frankel, J.R. and Wallen, N.E. (2006) How to Design and Evaluate Research Behavior in Education. McGraw Hill, New York.

[32] Pure Life Ministries (2017) How to Counsel Teenagers about Masturbation? https://www.purelifeministries.org/

[33] Tanton, C., Jones, K.G., Macdowal, W., Clifton, S., Mitchtell, K., Datta, J., et al. (2018) Patterns and Trends in Sources of Information about Sex among Young People in Britain: Evidence from Three National Surveys of Sexual Attitudes and Lifestyle. British Medical Journal Open, 5, e007834. https://doi.org/10.1136/bmjopen-2015-007834

[34] Laier, C. and Brand, M. (2016) Mood Changes after Watching Pornography on Internet are Linked to Tendencies towards Internet-Pornography Viewing Disorder. Addictive Behavior Reports, 5, 9-13. https://doi.org/10.1016/j.abrep.2016.11.003

[35] Devendra, S.E. (2017) Is Masturbation the Reason Why Some Teenagers Are Not Able to Gain Weight? What Are Pros and Cons of Masturbation? https://www.quora.com

[36] Kerkar, P. and Ffarcsi, M.D. (2018) Masturbation Addiction: Causes of Excessive Masturbation and Ways to Control It. 